\title{
Analysis of the Problems of the Chinese College Students' EFL Classroom Writings
}

\author{
Aiju Yu ${ }^{1}$ \\ ${ }^{1}$ Department of Foreign Languages, Zhengzhou University of Light Industry, Zheng Zhou, Henan, China \\ Correspondence: Aiju Yu, Department of Foreign Languages, Zhengzhou University of Light Industry, No. 5 \\ Dongfeng Road, Zheng Zhou, Henan 450002, China. E-mail: yuaijv@163.com
}

\author{
Received: March 15, 2012 Accepted: March 26, 2012 Online Published: August 27, 2012 \\ doi:10.5539/ies.v5n5p199 URL: http://dx.doi.org/10.5539/ies.v5n5p199
}

\begin{abstract}
This paper explores the problems of EFL classroom writings in the Chinese college teaching context from the perspective of textual organization and pragmatic strategy. Influence of their native cultural thought pattern causes the problem of discourse pattern and cohesion; lack of sufficient pragmatic strategy renders students' unawareness in writing purpose, genre, reader and style.
\end{abstract}

Keywords: EFL classroom writing, thought pattern, textual organization, pragmatic strategy

\section{Introduction}

EFL writing has been the focus of college English teaching for the last thirty years in China, and a number of writing approaches have been practiced: product approach, process approach, genre approach, task-based approach, content approach and process-genre approach. However, Chinese college students' EFL classroom writing abilities on the whole are weak compared with their listening and reading skills. Writing is a multidimensional communicative process, concerning "the generation, analysis, and synthesis of ideas; the organization of discourse; the control of sentence structure; the vocabulary, spelling, and mechanics" (Williams, 2007:12). In other words, writing is related to emotion, cognition, motivation, logical reasoning, linguistic skills and contextual adaption; it is also based on sufficient acquisition of English, so some people say writing can best reflect an individual's education. With the ever-increasing demands for English writings, such as academic and job applications, paper publications, personal and company introduction, Chinese college students are trained on EFL writing and spend much time on practice. It is of necessity to explore the problems of EFL classroom writings in the Chinese college teaching context.

EFL writing practice has two goals for Chinese students: one is language acquisition, the other is writing skill practice. For the former goal, teachers usually focus on linguistic accuracy and discourse pattern, and make students write from sentence to paragraph to essay. In this kind of practice teachers require that students write with a clear and rigid format: an introduction with thesis statement, supporting paragraphs, a concluding paragraph, sometimes some rhetorical devices like compare-and-contrast or cause-and-effect are used. For the latter goal teachers often focus on writing process, express of meaning and content. In EFL writing settings, the two goals may better be integrated, so that students can both pay attention to language competence, writing skills and content. Activities of writing are relevant to future school or life needs, so sometimes students may be assigned some target tasks based on authentic context: book reviews, reports, essays, memos, business letters, news articles and so on. In such writings writers may have to take into account of writing purpose, genre and audience.

In their EFL writing practice, Chinese students may make various errors in grammar, spelling, organization and writing strategy. This paper makes an analysis of the shared problems in college students' EFL classroom writings from the perspective of textual organization and pragmatic strategy. The writer found the problems are related to students' L1 thought pattern. The sample writings in this paper are mainly from the writing assignments of the second-year college students or from their national College English Test (CET).

\section{Problems of the Discourse Pattern}

A discourse is a grammatical, coherent piece of writing with clear and complete thematic information and certain communicative purpose and function (Liu \& Zhao, 2011). It is organized by thought pattern, and has a 
macro-structure. In other words, a discourse must possess a theme (thesis sentence), correct grammar, structure (cohesion and coherence), a purpose and genre. Linguistic studies show that the macro discourse pattern has much to do with thought pattern and discourse genre and that language, thought pattern and culture are closely connected. Language is influenced by thought pattern, and thought pattern by culture. So writing is a linguistic as well as a thinking process. Language is controlled by thought; thought pattern determines the writing pattern and rhetoric. Chinese college students learn English as a foreign language, their EFL writing pattern is inevitably affected by their native language as well as thought pattern. Some research reveals students' EFL writing process has bilingual features. Some students, in EFL writing, depend on their native thought pattern, structure, conception and process control. Native thought pattern accounts for $80 \%$ in process control, and over $50 \%$ in content and structure conception of their EFL writing (Liu, 2004). In the following parts we make an analysis of how the thought pattern of Chinese students influence their EFL writing.

\subsection{Chinese Thought Pattern and Students' EFL Writing Pattern}

English discourse pattern is generally direct and linear, with the thesis at the beginning and unified supporting details followed. The reader can understand the content and writing purpose at first sight. Compared with English writings, Chinese thought pattern is characterized by intuition and subjectivity, it is therefore spiral and circular, which leads to an indirect rhetorical pattern (Kaplan 1966). Kaplan suggested that L2 learners using single words or sentences correctly does not mean producing effective L2 paragraphs or essays because of their different ways of logical thinking. Their L2 writings can be largely affected by their own cultures, therefore it is not unusual Chinese students in their writings presents the background or objective conditions, and then state their own idea. That indirect way of thought pattern, or inductive way of writing, makes students place the main idea at the end of their writing. It results in a loss or confusion on the reader's part. S/He may not understand the purpose and thesis of the writing when reading the article. Look at a sample writing:

\section{Sample 1 Harmfulness of Fake Commodities}

Uncle Cheng is one of my father's close friends. One day he became ill and bought some medicine from a drug store. After taking the medicine, he didn't recover from his illness, instead, he became more seriously ill and nearly died. Why? It was because he bought the fake medicine. If people's lives are threatened by fake commodities, the whole society will be in disorder. Of course, only those who sell fake commodities will benefit from them. From this we can see that fake commodities are extremely harmful. Therefore, it's very important for us to make joint efforts to do away with them.

In this passage the student was affected by his Chinese thought pattern, that's why he wrote in a round-about way instead of stating his thesis at the beginning, but presented his main idea at the end of the paragraph; what's more, some irrelevant sentence was inserted, causing the paragraph disunified. In Chinese culture people value implicit artistic beauty in painting and writing, and the appreciation of art relies more on the reader's insight. This idea is transferred to EFL writing. Some students even regard the direct thesis at the beginning lacks flexibility and beauty. Chinese students' EFL writings are ambiguous in theme, and there are plenty of such examples in the national CET and postgraduate English entrance test.

\subsection{Thought Pattern and Flow of Thematic Information}

Once the topic is determined at the start in writing, the topic sentence should be developed. The flow of information is based on the known, which is arranged as the departure of information: the theme. The perspective is set on the topic and the theme; the information is progressed on. However, in their EFL writings sometimes even if students may write a topic sentence at the beginning, they cannot develop it. They shift the thematic part without any purpose, and the change of topic perspective affects the flow of information, even hinders the logical connection or smooth understanding. Look at Sample 2:

\section{Sample 2 The Importance of Extracurricular Activities}

First, extracurricular activities are a kind of learning process as well as relaxation. Students cannot be buried in academic books all day long. Extracurricular activities provide them with an opportunity to relax and to enjoy themselves. Another thing, there is no doubt that academic books cannot equip the students with every kind of knowledge they need in life. Extracurricular activities are a supplement and a different way of obtaining knowledge.

In the above sample, the perspective is shifted from 'activity' to 'students'and further to 'academic books', which results in the logical disorder and unclear information, causing difficulty and confusion to the reader on the main idea and purpose of the writing. 


\subsection{Thought Pattern and Cohesion}

In English writing the writer is supposed to determine his/her writing topic as $\mathrm{s} / \mathrm{he}$ sets pen to paper, and then develops the topic. The supporting sentences should be coherent in meaning and cohesive in form to each other. As a result, a lot of connectors like conjunctions, pronouns and adjectives are used to form explicit logical connection. To the contrary, Chinese belongs to the implicit connection of language. It does not resort to the linguistic forms of cohesion, rather, it relies on meaning cohesion, sometimes even contextual and pragmatic cues play the role of connection, so there are much fewer connecting words in Chinese writings. Influenced by their native thought pattern and writing habit, students cannot correctly use the connectives in their EFL writings. Consequently, their writings lack logic or coherence, which hinders understanding (see Sample 3).

Sample 3

A series of valves is opened, this allows the chemicals to mix, produce steam. The turbines start running. (Which really means: A series of valves is opened, and this allows the chemicals to mix and produce steam. As a result, the turbines start running.)

In Sample 3 the writer is obviously influenced by his Chinese way of organizing sentences; he did not use any connectors, which is fine and totally understandable in Chinese, though it is not good English.

\section{Problems of the Pragmatic Strategy}

According to linguists, pragmatic ability refers to the ability to identify the context and correctly understand the addresser's discourse and his purpose, and then appropriately express oneself in that context (He, 1997). Then how can pragmatic ability influence writing? What is the correlation of pragmatic strategy with EFL classroom writing? de Beaugrande \& Dressler (Liu \& Zhao, 2011) put forward seven criteria of discourse: 1) cohesion; 2) coherence; 3) intentionality; 4) acceptability; 5) informativeness; 6) situationality; and 7) intertextuality, three of which (intentionality, acceptability, situationality) are directly related to pragmatic ability. According to de Beaugrande \& Dressler, intentionality is the purpose of the text. A writer should be aware of his writing purpose. Acceptability demands that the writer take into account of the reader's role and their background knowledge; situationality means the writer has to consider the context, and write in appropriate style in relation to situation, culture and relationship. The variables of his writing include the purpose, genre, reader's background, relationship, context, syntactic structure, choice of diction and so forth. Personal pronouns, formality, acceptability, impersonality and politeness have to be taken into account. In communication people may adjust his strategy to the genre and textual organization based on his communicative purpose, readers and the context. If the author's intent is to explain a phenomenon and provide information to the reader, s/he will likely use a formal and impersonal style, using vocabulary that is neutral and an expository format to present his/her argument. If the writing purpose is to persuade the reader to buy something, like advertisement, he may use some words to create a kind of humorous and intimate tone to realize his purpose, the structure of the sentence may be simple.

Chinese students have dual EFL writing goals: for acquiring linguistic knowledge like grammar rules, vocabulary use, and rhetorical patterns; for acquiring writing skills for future real-world needs, like writing reports, memos, business letters, news articles and so on. The goals not only set the purpose but also the reader of EFL classroom writing ----- the teacher as well as virous readers in the social context. So EFL classroom writing is supposed to focus on purpose and reader, especially reader's potential response is to be considered.

In classroom EFL writings, students make a number of pragmatic errors: confused writing purpose, generic inappropriateness, lack of consideration for readers, inappropriate rhetoric style. We are going to deal in this part with the problems of writing purpose, and lack of reader, generic and stylistic awareness.

\subsection{Ambiguous Writing Purpose and Generic Unawareness}

Writing, like conversation, satisfies people's need of communication. It may be a speech, a thesis paper, an advertisement, a novel. The purpose of writing may provide information, or convince people or build a good relationship. Different intention may require different genre and different style of writing in relation to situation, people, modality, rhetoric and structure. There are traditionally four types of writings: description, narration, exposition and argumentation. Each has its own style. A writer should be able to choose his intention, situation, potential reader and comply with his style. It may be graceful, humorous, accurate, formal, objective, depending on those variables. However, Chinese students neglect the factors in their EFL classroom writing. They seem to prefer the writing of narration. When they are assigned a writing topic, which is meant to write a piece of exposition or argumentation, they often start with a story instead of a thesis sentence like that in the above Sample 1. The diction they use often appears to be very evaluative. 


\subsection{Lack of Reader Awareness}

According to the interactive writing theory, writing is the communication between the writer and the reader. It is a process in which the writer conveys in writing his thought and requirement to his reader, and makes them understand, identify and accept, the writer thus has to consider the relationship between himself/herself and the target reader, or possess reader awareness. He conceives of his potential reader and tailors his material for reading convenience and reader's psychological needs. Some people say reader awareness is an indication of sophistication of the writer: it helps in building or maintaining the relationship with the reader so as to realize one's writing intention (Deng, 2008). Reader awareness is gradually developed into a key factor for judging writing, because only when the reader finishes his reading is the writer likely to achieve his purpose. Reader awareness demands that the writer should try to assess his writing in the reader's position. He should handle writing within the reader's convenience and understanding, consider the reader's feeling, cognition, taste, needs, context and culture, so as to organize his syntactic structure and diction accordingly. However, in EFL writing, Chinese students fail to consider the reader's need and habit, which renders the person, mood and modality problems. For example:

\section{Sample 4}

If you study throughout night you will feel tired. How can we make our body and mind healthy? I think doing sports is the best way. Every morning you should get up early, then you should drink a glass of water and do some morning exercises.

In the above sample, the writer changes the personal pronoun several times, which may complicate understanding. Moreover, his intention is to advise the reader to do morning exercise, the modal verb 'may' or 'would' can better satisfy his purpose. The use of 'should' is a strong tone, as if it were a duty to the reader. They may hence be irritated by the strong words. In the English culture 'may' would be more objective and acceptable, therefore it can help the reader better understand the information and the writer better achieve his purpose.

\subsection{Lack of Stylistic Awareness}

Unlike English, which has a number of ways to raise the degree of formality of discourse such as by using words of affixation or structures of passive voice and coordination, Chinese has small stylistic changes between different structures. Influenced by their native language rules, Chinese students are not aware of the stylistic distinctions between different words or structures of similar words. In EFL writings they often use words and structures of a low formality degree. For example, in the CET in 2000, students were asked to write a composition entitled Is a Test of Spoken English Necessary? A student who got 11 scores out of a total 15 wrote like this (Cai, 2003):

\section{Sample 5 is a test of Spoken English Necessary?}

A test of spoken English is necessary. If you ask me why, I'll tell you there are lots of reasons. Let's look at something in job markets. And if you can't speak English, you can't get a good job. Don't you believe? Then another is to communicate with foreigners. You know, if you can't speak English, how can you make your idea understood by them? Anyway, spoken English is getting more and more important. So a test of spoken English is important.

From his score we may see this is a relatively good student. Either because of the influence by his native language rules or because of insufficient English acquisition, his writing is very colloquial. Some students still exhibit features of spoken English even in writing of an argumentation. Besides, Chinese students prefer to use verbs rather than nouns, though nominalization is an indication of a formal style.

\section{Conclusion}

In China the study of discourse and pragmatic problems in college students' EFL classroom writings has been relatively overlooked. Teachers in the classroom often concern themselves with grammatical or lexical issues like tense, sentence structure, or the usage of lexicon, neglecting the structure and pattern of the writing. This paper analyses the discourse and pragmatic problems existing in Chinese college students' EFL classroom writings concerning cultural differences. More attention should be paid to the distinction between Chinese and English culture. With the teacher's help and student's awareness, this problem can be solved and students' writing improved.

\section{References}

Cai, Jigang. (2003). A contrastive study between English and Chinese rhetorics and writing. Shanghai: Fudan University Press. 
Deng, Zhiyong. (2008). Review of Burke's rhetorical thought. rhetorical studies, 6, 15-23.

He, Ziran. (1997). Pragmatics and English learning. Shanghai: Shanghai Foreign Language Education Press.

Kaplan, R. B. (1966). Cultural thought pattern in intercultural education. Language Learning, 16, 1-20. http://dx.doi.org/10.1111/j.1467-1770.1966.tb00804.x

Liu, Chendan., \& Zhao, Xiufeng. (2011). What is text linguistics. Shanghai: Shanghai Foreign Language Education Press.

Liu, Kuanping. (2004). Effects of different thought pattern on Chinese student's EFL writings. Foreign Language Research, 5, 18-25.

Williams, Jessica. (2007). Teaching writing in second and foreign language classrooms. Beijing: World Publishing Corporation. 